\title{
Neck Edema, CTCAE
}

National Cancer Institute

\section{Source}

National Cancer Institute. Neck Edema, CT CAE. NCI Thesaurus. Code C143700.

A disorder characterized by swelling due to an accumulation of excessive fluid in the neck. 